\title{
Community Treatment Orders and social factors: complex journeys in the mental health system
}

\author{
Philip Haynes* and Julia Stroud \\ School of Applied Social Science, University of Brighton, Brighton, UK
}

Community Treatment Orders (CTOs) have developed rapidly in England and Wales to become a substantial legal intervention. Mixed methods were used to analyse CTOs as one intervention in a complex mental health system and its relationship with social factors. CTOs are used more than expected, with a high number of revocations and renewals. Less than half of CTOs are discharged on time. Service users experience multiple social disadvantages and isolation. They value the stability of a relationship with a care coordinator, but are ambivalent about medication, and can have negative feelings about coercion. Those experiencing recovery tend to initiate social activities, but have poor engagement in care plans, tribunals and reviews. CTOs reduce compulsory hospitalisation, but give rise to human rights issues in the community. Without major social investment to support those with chronic mental health conditions, CTOs may remain the best compromise to balance the demands and requirements of legal and health policy.

Keywords: Community Treatment Order Complexity Theory Social Factors User Perspectives

"This is an Accepted Manuscript of an article to published by in JOURNAL OF SOCIAL WELFARE AND FAMILY LAW by Taylor and Francis at https://www.tandfonline.com/loi/rjsf20 in late 2019.”

*p.haynes@brighton.ac.uk 


\section{Introduction}

The aim of this paper is to explore the role of Community Treatment Orders (CTOs) as implemented by the Mental Health Act 2007 (section 17A) in England and Wales, locating this within wider policy. It is argued that the mental health system is an example of a complex social system. The operational use of CTOs has many of the features of conceptual complexity as argued by researchers who theorise this approach (Plsek and Greenhalgh, 2001; Edgren and Barnard, 2012; Tsasis et al, 2012; Sturmberg, et al, 2012; Haynes, 2012; Hyojung, et al, 2017; Ellis, et al, 2017). A previous Economic and Social Research Council (ESRC) project applied complexity theory to a range of policy case studies (Darking, et al, 2018; Haynes, 2015). The recent ESRC and UK government funded, Centre for the Evaluation of Complexity across the NEXUS (CECAN) takes the application of complexity based understanding of central government policy process and outcomes into many areas of the UK civil service (https://www.cecan.ac.uk/). Complex systems theory was conceived in the natural sciences, for example to understand weather systems (Lorenz, 1963), and many applications have followed across a wide range of disciplines and interdisciplinary arenas (Simon, 1962). Attempts to apply complex systems theory to mental health policy are in their infancy (Ellis, et al, 2017).

As stated, CTOs were introduced by the Mental Health Act 2007 (section 17A) and allow service users to be treated in the community rather than hospital. They are an evolution of social policy and law that seeks to treat as many as possible in the community (Rogers and Pilgrim, 2001).

Community Treatment Orders allow the Responsible Clinician (RC) to discharge a detained patient who has been on a treatment order from hospital while still subjecting them to various forms of compulsion and coercion in the community. For example, the patient remains liable to recall to hospital by the RC and is subject to conditions while on a CTO. These conditions are aimed at ensuring the patient receives medical treatment and/or prevents risk of harm, and/or protects other persons. Failure to comply with conditions can lead to recall to hospital. 
Section 17A stipulates conditions to which the service user must adhere. As indicated, the most common condition requires the patient to take medication and Section 17E gives the RC the power to recall a service user to hospital for treatment, if they need this, if there is risk, or a condition is broken. In this situation, a CTO can be revoked and the hospital treatment order reinstated. A common practice is the renewal of CTOs beyond their initial six months duration (Stroud and Haynes, 2018). After a renewal of six months, a CTO can be renewed for periods of 12 months (Sections 17C, 20A). The Independent Review of the Mental Health Act in 2018 raised concerns about the implementation of CTOs (Wessely, et al, 2018). It was concerned about the large number of orders made, and the disproportionate use of CTOs for 'Black' and 'Black British' people. It has proposed further considerations for review and suggested that a modification of legislation may be needed in the future to ensure CTOs are used more appropriately.

\section{The systems intersection}

The management of CTOs is located between two systems, the mental health legal system and mental health treatment system. Luhmann (1995) observed the restricted ways that actors could communicate across differing social systems. The language of psychiatric diagnosis, and the techno-social concepts of the legal profession, are two examples of restrictions to communication. Luhmann likens this to 'autopoiesis' in a physical system where a separate cell maintains itself. Autopoiesis is 'self-referential' as it maintains independence, but this also requires closure. Communication across system boundaries is then restricted. Systems communicate via 'structural coupling' that 'does not violate their operational closure' (Moeller, 2006, p. 37). Luhmann used the example of the 'law' being coupled with the 'economy', through taxes. Our interest is how mental health law communicates with health and welfare. Building on the interpretation of (Moeller, 2006, p. 29), the legal system is seeking consistence with social norms and regulating conflicts, while the health system is maintaining and improving health and wellbeing. Mental health law is coupled to health and welfare through the 
principle of 'treatability'. For example, s17A(5) states that one of the criteria for making a CTO is that the patient is suffering from a mental disorder of a nature or degree which makes it appropriate for him to receive medical treatment. This is the idea that the law should not intervene unless it can offer evidence for improving health and welfare. The CTO promotes treatment in the community, even when the treatment is against the service user's personal wishes, but when it is viewed by legal authority in the form of the Responsible Clinician and Approved Mental Health Professional to be necessary for the reasons stated in section 17A (5). This states that a CTO and treatment must be necessary for the patient's health and safety or for the protection of other persons.

\section{A complex systems perspective}

The policy system environment, scale and structure

Complex systems have key defining characteristics (Cilliers, 1998, p. 3-4). Systems are inhabited by 'cases', like human agents (Plsek and Greenhalgh, 2001, p. 625) and social organisations. In the mental health system, key actors are service uers and mental health practitioners (and this includes clinicians with formal legal responsiblities). Cilliers (1998) notes that history can have a strong effect, creating 'path dependencies' (Mahoney, 2000), and futures determined by earlier influences. Historical legal principles often dictate the incremental changes to new laws. Mental Health legislation has progressed incrementally in England and Wales in this way, strongly influenced by previous principles. A structure underpins the operation of social systems. This includes 'places' like hospitals, and the 'products' of pharmacology. Systems exist within a larger environment. Mental health policy co-exists with many other social system structures like the law, housing and income benefits (Walby, 2007).

Complex social systems are layered, with different levels of operation and degrees of scale. Mental health services are organised geographically by the NHS. Some areas will decide to use CTOs more than others (Stroud and Haynes, 2018). Systems relationships are 'horizontally interdependent' and 'vertically nested' (Nohrstedt and Weible, 2010, p. 8). Local NHS trusts still relate to a national health and law. At one extreme, systems can be 'scale free', 
where a single event has major implications for the whole system regardless of locality: reviews of existing legislation and new legislation would be examples. More often, system dynamics, like the operation of local community mental health teams, are local, but with similarities and differences between areas. Walby, (2007, p. 459) notes that complex social system structures can overlap, with social relations having 'a different spatial and temporal reach'. This results in dynamic patterns of similarity and difference.

\section{Relational system interactions}

The relational aspects of systems are an important defining feature (Castellani and Hafferty, 2009). Social systems are defined by their interpersonal communications (Luhmann, 1995). Nohrstedt and Weible (2010, p. 7) note the importance of the relative degree of 'integration' and ‘alignment' for practitioners and users within each policy system. Systems analysts like Meadows (2009) investigated the interaction patterns in relational structures. Reinforcing feedback was the affirmation of behaviour, like making CTOs. Balancing feedbacks are messages that check the behaviours. For example, in the mental health system, reports from centralised monitoring that suggest too many CTOs are being made, without enough use of discharges, seek to balance the enthusiasm of practitioners in their use of the provision (NHS Digital, 2017).

\section{Limited information and multiple perspectives}

Each actor and organisation has a limited knowledge and information about the system. None has a full and complete view. There will be conflicting perspectives. Activity is engaged in resolving conflicts and bringing a dominant sense of purpose (Meadows, 2009). It is imperative that policy is understood in relation to user perspectives. It is possible for social systems to become dysfunctional and to deliver the opposite of what they intended (Squires, 1990). In our research, there is a commitment to include the user perspective, as the 'systems lens' through which those subject to a CTO view the world (Stroud, et al, 2015; Banks, et al, 2016). 


\section{System order and disorder}

Social systems exist in a paradoxical state of order and disorder. Order comes from shared values, logics, and adherence to rules (Kontopoulos, 1998). It results from 'attractors', where an attractor is a force that creates patterns of order (Sturmberg, et al, 2012; Boulton, et al, 2015; Ellis, et al, 2017). Patterns of behaviour are dynamic, in part because the nature of complex systems is that they have numerous attractors influencing them in different ways at different times.

The emergence of order from attractor forces is an important part of functioning social systems. For example, central government may establish a new legal practice like the CTO, but local interpretation by professionals will determine the detail of the actual implementation of the legal procedure. Forms of resistance to change, or dissipative innovations that drive change, can emerge from the ‘bottom up', via the ‘self-organisation' of citizens and practitioners (Teisman, et al, 2009). This fits with the conclusions of 'Street Level Bureaucracy’, (Lipsky, 1980; Breit, et al, 2016) that much of policy evolves according to those in practice, as they interpret how law will be implemented. For example, research has found that CTOs are being used more than government had expected (Wessely et al, 2018). This illustrates the interactive dynamics in the social experience of complex systems and the power of policy actors to self-organise their response.

Complex social systems are dynamic with futures that are emergent, offering multiple possibilities that are largely unknowable, but the identification of repeating patterns can provide insights into the likely trajectories that systems will take. When new legislation is implemented it is not possible to predict with a high degree of precision what will happen, but policy makers can evaluate the trends and speculate about the range of likely outcomes and future possibilities. Different outcomes may occur in different places, with some patterns being small scale and temporary, while other patterns might be national, and some outcomes more permanent than others. 


\section{Methods}

The research aims of the study to be reported were:

(1) To identify and understand the factors, particularly social care and social environmental factors, associated with the discharge or renewal of a CTO and with recall to hospital.

(2) To identify the social interventions and support which are provided and to explore whether these are experienced as helpful by service users, in order to inform good practice.

(3) To explore and understand whether relationships (personal and professional) or loneliness are influential in CTOs being renewed or discharged, or there being a recall to hospital.

\section{Research design and data collection}

There are links between complex systems approaches and critical realism (Byrne and Callaghan, 2013; Haynes, 2017). Critical realism places causal mechanisms into a social context and recognises the temporal and spatial limitations of mechanisms (Pawson and Tilley, 1997). 'Causal contingency’ (Ragin, 1987; Rihoux and Ragin, 2009) goes further. The focus is on finding patterns rather than causal mechanisms. Patterned order results from social relations, rather than a deterministic causality (Haynes, 2017). In mental health law and mental health systems, service user behaviour patterns will be determined by a dynamic range of medical and social factors that influence outcomes.

Complex systems research collects different perspectives from a range of actors. This gives a broad representation of what the system is like. After this, exploration may proceed to suggesting policy interventions, while assessing the probabilities of the likely impact (Darking, et al, 2018; Seddon, 2008; Hawe, et al, 2009).

In common, therefore, with many research designs resulting from complex or critical realist ontology, this research used mixed methods (Haynes, 2008; Sanderson, 2000). Data were collected between May 2016 and June 2018. There were three elements to the data collection. First, a contextual study of secondary data about the incidence of CTOs and related 
demographics. This included data analysis at both national and local levels. Second, the research carried out a regional cross-sectional survey of practitioner perspectives on factors influencing their decisions. Third, the researchers conducted qualitative interviews with practitioners and service users. Together this described the social systems where CTO activity occurs and facilitated analysis of the current situation.

Ethical approval was granted by the following ethics and governance committees: University of Brighton; South East Coast and Surrey, NHS (IRAS 196566); and Sussex Partnership Foundation NHS Trust. All participants gave consent for their data to be used in this research.

\section{Secondary national and local data collections}

National data for England of CTO activity is used as collected by the Health and Social Care Information Centre (HSCIC) and published in two different key sources (Care Quality Commission, 2016). In addition, local data from one large NHS Mental Health Trust was made available for 340 CTOs made in a two year period (2013-2015). Some of these orders were repeated for the same service user $(\mathrm{n}=68)$. Statistical analysis was undertaken using Microsoft Excel and IBM SPSS v24.

\section{An online survey of mental health practitioners}

An online survey of all Responsible Clinicians (RCs) and Care Co-ordinators (CCs) administered in three Mental Health Trusts across one English region returned data for 181 respondents. Sixty four were RCs and 119 were CCs. Seventy seven (42\%) were psychiatric nurses, 54 (30\%) were psychiatrists and 35 (19\%) were social workers. Forty three percent of the sample were aged $45-54$ years (76) and 57\% were female (100). Thirty percent (59) described themselves as being from an ethnic minority background, including 9\% (16) recording that they were ‘Black African’ or ‘Black British’. Thirty four percent (61) had over twenty year's relevant professional experience and 78\% (138) had over ten years. 
The survey asked practitioners questions about the influence of social and other factors when making decisions about discharge, recall and revocation of CTOs. These questions presented a series of statements signifying a point of evidence that might influence making a specific legal decision and then asked practitioners to rank the significance of the statement on a five point ordinal scale. For example, when considering the discharge of a CTO, did they see good engagement with mental health professionals as: not at all significant, slightly significant, quite significant, very significant, or, extremely significant. There were 27 of these types of questions, covering the key sub groups of CTO decision making like: discharge, renewal and recall. Additional questions captured demographic data like the practitioners’ professional background and employment, and the amount of time they had spent in a specialist practitioner role. Quantitative data was analysed using SPSS v24 and using a variety of statistical methods.

Qualitative interviews with mental health practitioners and service users Semi structured interviews provided qualitative data about the views of 41 practitioners and 16 service users. Interviews with practitioners included 17 RCs (usually psychiatrists) and 24 CCs. The CCs included 16 community psychiatric nurses, 7 social workers (6 were Approved Mental Health Practitioners) and 1 occupational therapist. These interviews were tape recorded, transcribed, and analysed using thematic analysis (Braun and Clarke, 2006), assisted by NVIVO software. Research governance approval only permitted the recruitment of service users into the research via their practitioners. The limited user response $(n=16)$ suggests that those interviewed were more likely to be engaging positively with their CTO.

\section{Results}

\section{The national 'macro' policy system}

National trends, since CTOs began in 2008, indicate that the annual number of orders in England steadily increased through 2010-2015 and then plateaued at approximately 4,500 per 
annum (see figure 1). The number of CTOs then rose again in 2016 to 5,426. The approximate rate of national orders being discharged per year is 2,500. National data raises concerns about a disproportionate number of black and ethnic minority service users being placed on CTOs (Wessely et al, 2018).

\section{Insert figure 1 here}

CTOs have grown to be a key area of mental health law activity in a relatively short period of time. While several thousand CTOs are made each year, this can be compared to tens of thousands of s3 hospital treatment orders. Section 3 of the Mental Health Act allows for the detention of a service user for treatment in hospital if specified legal criteria and conditions are met. Treatment cannot be given against the service users will, without the legal order being in place and appropriate treatment must be available in the setting where it is applied. A section 3 hospital order lasts for 6 months, renewable for a further 6 months and thereafter for a year.

There were 25,577 detentions under mental health legislation to mental health institutions like hospitals in 2015-16. In 2014-15, 95\% (n=4,323) of CTOs were made following a section 3 hospital order: other CTOs followed different treatment orders, such as s37 hospital orders. There are considerable regional and local variations in the making of new CTOs, both in relation to the population size and the number of hospital orders made. Figure 2 shows, for local organisations registered with the CQC as a NHS mental health service provider in England and Wales, the ratio of CTOs made in 201415 as compared with all Mental Health Act hospital orders. There was a wide variation, with those above the regression line in figure 2 having an above than expected ratio of CTOs compared to the number of local hospital orders. From the 53 organisations 
included in this analysis, the mean number of CTOs was 96, the median 95 and the standard deviation 54. Further examination of the trend data of these ratios between 2010 and 2015 showed no evidence of a convergence between areas over the five years (http:www.hscic.gov.uk).

Insert figure 2 here

National datasets indicate twice as many men than women were subject to a CTO and the largest age frequency was for those aged 35 to 49 years. Those made subject to CTOs are relatively older in age than other mental health service users (NHS Digital, 2017). There is a disproportionate number of CTOs made for those from an ethnic minority (Care Quality Commission, 2016). The Independent Review of the Mental Health Act has estimated that 'Black and Black British' people are nine times more likely to be made subject to a CTO than white people (Wessely, et al, 2018).

\section{Local policy implementation: the NHS Mental Health Trust}

It is at the organisational level that policy is implemented. In England and Wales, the focus for policy implementation is NHS mental health trusts, working in partnership with local authorities and voluntary organisations.

Local area census data was made available to this research project from one large NHS Mental Health Trust in England. This covers a mixed urban and rural population with over 1.8 million residents. The local dataset showed that the majority of CTOs were renewed beyond six months with the average length of a CTO being 7 months, and the maximum for one order being 37 months. The distribution is skewed by the large number of orders that end prematurely because of recall and revocation. The same NHS mental health trust area dataset showed that 
over a two-year period, 39\% (133) of orders were discharged, a little below the national proportion. As many as $26 \%$ (89) of the area sample were recalled and their CTO revoked, this suggesting, in line with Burns, et al. (2013) that CTOs do not necessarily result in stable mental health for a sizable minority. Bivariate analysis showed no evidence of CTO outcomes having a statistically significant relationship with demographic factors like gender, age or ethnicity.

The twenty per cent of users found to have been subject to more than one CTO ( $n=68)$ were less likely, with subsequent orders, to have the CTO concluded with a discharge (23\%/15). There was also a higher chance of the service user being recalled and the order revoked (35\% /25), and an increased chance of fatality (4\%/3).

The local data indicated social isolation. Seventy seven per cent (256) reported their relationship status as single. Only $14 \%$ (34) were living in a communal and/or supported environment, and $13 \%$ (30) were living with family members, and 7\% (17) were homeless. There was a very high rate of occupational inactivity. Only $2 \%$ (5) were working full time; $1 \%$ (3) part time, $0.5 \%$ volunteering.

The area data showed that CTOs were more likely to be made to men $(65 \%$ / 221) than women. The average age for being on a CTO for men was 43 years, compared to 51 years for women. In summary, the area data illustrates that people subject to CTOs have previous experience of mental health difficulties and face challenging social factors.

\section{The mental health practitioner's perspective}

The area online survey of practitioners provided evidence of the homogeneity of views about managing CTOs. When the major professional groupings of psychiatrist, psychiatric nurse and mental health social worker were compared, there were no statistically significant differences in the perspectives that influence major CTO decisions. Similarly, there were no differences in perspectives about what should inform decisions when comparing the roles of RC and CC.

Over 90\% (163) of practitioners reported that they perceived the patient taking medication and having engagement with services as 'very' or 'extremely significant' factors to influence decisions about discharge. Social factors had less total impact in terms of their 
combined influence on discharge decision making, though were viewed as providing evidence for or against discharge or renewal. Reported as 'very’ or 'extremely significant' factors included; 54\% (98) appropriate accommodation; 51\% (91) the service user having positive social activities; and 41\% (73), having a meaningful occupation.

There was considerable similarity in views about renewal. Over 83\% (147) said that the service user's lifestyle being chaotic was a 'very' or 'extremely significant' factor when deciding to renew an order beyond six months. $80 \%$ (145) gave the same scoring to 'the service user being unwell or not always accepting the need to take medication'. Recreational drug use (49\%/88) and social isolation (47\%/82) were less likely to be scored as 'very' or 'extremely significant' influences. When asked to rate the importance of factors that might influence a decision to recall, homogeneity was also evident. The leading influences (rated as 'very’ or 'extremely significant') on recall were risk to self or others (99\%/179) and concerns expressed by the carer, family and/or friends (87\%/157).

In-depth interviews with professionals confirmed the importance of engagement by the user with professional relationships, compliance with medication, and insight into the need to take medication to reduce risk, as the key behaviours when judging the success of a CTO and the possibility for discharge. Practitioners reported the importance of relationships, and building such relationships, alongside the need to achieve compliance with medication.

A large minority of practitioners interviewed (17/41\%) recognised that being subject to a CTO might impact patient's self-esteem and thereby contribute to the social stigma associated with a mental health condition. Some practitioners reported a concern that CTOs might be made to free up limited mental health beds (10/24\%). Some reported a considerable pressure on resources and reducing availability of support in the community (12/29\%). The lack of availability of beds could also influence CTO recall decisions (22/54\%).

Findings from the in-depth interviews with practitioners largely supported the survey data and added important detail to it. Care Coordinators in particular emphasised the importance of their professional relationship and commitment to service users describing this as a 
'relational model' (CC 14 and 22) and as one CC summarised it: 'I think we value our relationship with people more than anything' (CC 04).

Practitioners saw a range of social factors as influencing their decisions about the management of CTOs, for example when considering discharge: 'looking at social factors helps create a...holistic picture of...where the service user's at' (CC 04). Engagement in social activities, being in stable accommodation, and contact with carers, family and friends was generally seen as positive, whereas involvement with alcohol and drugs was not.

Responsible Clinicians and CCs acknowledged that service users did not always feel positive about being on a CTO, that it could negatively affect their sense of self and be related to the social stigma experienced by those with mental health difficulties; for example reporting a service user who said: 'I can't believe I've got to do this'(CC 24). But on balance, practitioners see the negatives as relatively less when compared with detention in hospital and that there were advantages, therefore, with being supervised in the community.

In general, practitioners perceived that they worked well together, but acknowledged that there could be communication and logistical challenges when patients were leaving hospital and resource availability could influence decision making. For example, making a CTO to 'free up' (CC 22) bed space for a patient in greater need.

The primary influences on practitioners are: risk, insight and the use of medication and compliance to reduce risk. Social factors are acknowledged as important and are considered as evidence for and against discharge, but they are lesser considerations for those with responsibility to manage CTOs. The findings from our organisational data replicate aspects of previous research (De Riddler, et al, 2016).

\section{The experience of mental health service users}

Service users are on 'the receiving end' of CTOs and the key policy question is whether, as a less restrictive alternative, these relatively new legal orders manage risk and increase the liberty and welfare of patients, when compared to hospital detentions (Hatfield and Antcliff, 2001). 
The 16 research interviews with service users revealed some shared views of CTOs, but it is important to remember that a large number of service users invited by their practitioner to take part declined ( $\mathrm{n}=50$ ), most likely because they did not feel positive about being subject to a CTO. The user cohort interview results are, therefore, highly likely to reflect the views of those feeling more engaged and positive about their CTO. Most of the service users (SU) interviewed reported experiencing psychosis.

The dominant discourse reported by the service users, like practitioners, was that their CTO was about compliance with taking medication. 'I left hospital on a CTO, just 'cos that's what they do...they put you on a CTO...to make sure you take your meds' (SU09).

Those interviewed expressed varying degrees of negativity about the medication they were prescribed. 'I always think - no more medication' (SU14). In the interviews, participants would also often acknowledge the paradox that medication could have positive outcomes: ' $I$ have got to a place where I am happier about my medication' (SU03). Service users associated medical doctors with medication and therefore expressed ambivalence about their relationship with the RC.

Being on a CTO could have negative effects on agency and sense of self. Service users were aware of conditions requiring them to take medication, but not always aware of other conditions, and did not report enthusiastic engagement with the participatory elements that the CTO provides. Service users told of a sense of not having a voice. For example, they did not perceive care plans as increasing their involvement and engagement: 'there probably is a care plan, but I probably didn't even take notice of it' (SU10). Similarly, service users reported being 'talked about' (SU03, SU15) in tribunals and felt that their opinion was not directly sought.

In general, service users described social activities as helpful in providing a structure to their lives and a chance to build social contacts and relationships. The cohort reported a diverse range of activities most of which they perceived they had organised for themselves rather than resulting from professional help or as part of a care plan. Those who self-selected via practitioners to be interviewed were clearly, to some extent, engaged with recovery. The diverse range of social activities reported by the cohort included part time work or volunteering, 
studying at college, and attending religious organisations. Relationships with family and friends were seen as important, perhaps depending on one key contact who had remained in communication through their long-standing difficulties. For others, relationships in supported housing offered a significant interaction. In some interview accounts, key relationships had been renewed because of the stability afforded by the CTO.

The most important finding from the interviews with service users was the reporting of the helpfulness of their relationships with care coordinators. 'Any kind of dire situation, I can contact the AOT...they would be there for me' (SU13), and similarly, 'it's good that I have so much support' (SU14). While service users reported not being heard in the formal procedures of the CTO and its review process, they felt that their on-going relationship with the CC provided evidence of being listened to and cared for.

Overall, attitudes from the service users interviewed towards their CTO was pragmatic and more favourable than adverse. The interview transcripts often displayed this evidence as paradoxical, or as apparent ambivalence, with the most positive comments being about their social relationships, contact with the CC, and feelings that their own life was more settled and stable. Negative comments were about medication and a lack of confidence in the formal procedures associated with the CTO.

\section{Discussion}

Whether or not one evaluates CTOs as successful depends on what outcome one expects the policy of CTOs to achieve. Complexity theory raises the likelihood of contingent causality: that there will be clustered and contradictory patterns of outcomes, rather than singular and aggregated outcomes (Ragin, 1987; Haynes, 2017). The UK Government in the mid-2000s, before legislating on CTOs, was strongly influenced by media coverage of a small number of homicides attributed to those with a severe mental health condition living in the community and not being treated. In this sense, the political influence on the policy was motivated by the 
reduction of risk (Dixon, 2015). Research into homicides attributed to mental health patients from 2005-2015 noted a fall after 2007, although that research cannot link the trend to the introduction of CTOs in England (National Confidential Inquiry into Suicide and Homicide by People with Mental Illness, 2017).

A meta review of more than 50 international studies concluded that there was no conclusive benefit from CTOs when considering a wide variety of possible outcomes, including number of readmissions, relapses in mental health conditions, the total time spent in hospital, and the period of time when liberty is restricted (Rugkasa, 2016). But it would be surprising if CTOs, achieved an aggregate success. Rather, it is likely, given the stark social environment of service austerity in which CTOs are situated, that a sub set of CTOs are successful. Previous research that focused on improving social isolation for those on a CTO, criticised their inability to increase service user's social network size (Vergunst, et al, 2017). But this is a limited outcome focus and not the primary purpose of CTOs, where the legal focus is facilitating continuing treatment in the community. While Burns et al (2013) concluded in the large-scale OCTET study that CTOs did not reduce admissions to hospital, Awara, et al, (2013) concluded from a small scale study that they did.

\section{The policy system environment, scale and structure}

CTO service users face major challenges in the wider social environment before one considers the impact of mental health law and treatment interventions. A complexity 'perspective' (Boulton, et al, 2015) limits the idealism about what can be achieved by the 'structural coupling' of mental health and law. The social context is that experiencing a severe and persistent mental health condition, creates social stigma associated with isolation, and the consequence of reduced opportunities for relationships, social networks, occupation and appropriate accommodation (Salehi, et al, 2018). These aspects were evidenced by this research. This is a complex scaling of contextual social disadvantage that restricts what the CTO can achieve as a policy intervention. 'The selective adoption of complexity notions enables...multiple systems of inequalities in the same space or institutional domain' (Walby, 
2007, pp. 466-67). In short, the CTO is a social policy 'sticking plaster' and cannot be expected to quickly turn around multiple social and health disadvantages.

\section{Limited information within the system and multiple perspectives}

The 'structural coupling' of law and health in the CTO is a policy control device that seeks to reduce risk to self and others via the potential stabilising effects of prescribed medication. However, it does this by compromising the civil liberties of the patient. The patient is no longer held as a resident in an institution, but their liberty is still curtailed by them being required to take medication, receive supervision, and being subject to a power of recall to hospital. Given the specific policy coupling of a vehicle like the CTO, its outcome potential is highly likely to be disrupted by other external social dynamics and this will undermine its probability of 'success'.

The main criticism of CTOs is ethical; a concern about the libertarian disruption of human rights (Burns, 2009; Rugkasa, 2016), but this ignores the multiple intersectionality of social inequality, as Walby (2007) alludes to in her complexity sociology. Humanity for the mentally ill is greatly compromised in wider society - as well as in precise legal interventions. The under resourcing of mental health and related social services increases reliance on coercive interventions despite the aspiration to realise and maximise involvement in decision making for all service users as demonstrated in the United Nations Convention on the Rights of Persons with Disabilities (Disabilty Rights UK, 2017; Weller, 2011).

\section{System Order and Disorder}

The homogeneity of professional views found in our research is evidence of a consistency of decision making with CTO discharge, recall and revocation. Zafonte and Sabatier (1998) note the importance of shared beliefs for policy and practice coordination. The 'popularity' of CTOs with practitioners, in terms of their volume use, does not translate to 'success' but is evidence of a shared pragmatism, given an awareness by practitioners also of the social constraints that 
limit the usefulness of a quasi legal intervention (Janson and Fridlund, 2016). Service users express conflicting views to professionals about the value of medication, but see potential when living in the community as opposed to being in hospital, and in the opportunity to have a sustained relationship with a professional care coordinator (Gibbs, et al, 2005). The high rates of CTO recall, revocation and renewal evidenced in this research, and relatively low rates of discharge, can be explained by the detailed concerns practitioners have about balancing risk and patient rights in their daily practice. CTOs are percieved as sometimes delivering a form of order to the social and system instability that practitioners and service users experience.

The pragmatic reality in a social world with limited public resources and a sub population of citizens with severe mental health issues is that CTOs often seem the least negative choice from the limited choices available. As DeRidder et al, (2016, p 123), argue, clinicians feel pressured to use CTOs to avoid risk and negative outcomes. A pragmatic approach to risk and treatment compliance, in an operating environment with limited resources, is an 'attractor' logic that has made the use of CTOs more popular than was envisaged (Dawson and Mullen, 2008). The reduction of risks could be achieved by other macro scale social policy interventions over time, such as promoting community and neighbourhood services, better supporting service users in a precarious employment market, and creating more affordable, supported accommodation (Stull, et al, 2012). But these approaches are beyond the specific structural coupling in the CTO and are the domains of larger socio - economic systems.

\section{Conclusion}

The mental health policy system is a complex public service, comprising the operation of the legal system and its interactions with the health service. The activity of CTOs is a juxtaposition of the legal mental health and NHS health systems. 
Both these systems operate within, and are permeated by the wider social and economic environment, and therefore social issues such as employment, unemployment, relative poverty, accommodation, social networks and relative isolation are determinants about what happens to mental health service users (Salehi, et al, 2018).

The CTO is the containment in the community of severe mental illness that is associated with chronic ill health and substantial social deprivation. Law drives the CTO process. It is defined by risk, containment and 'harm reduction' for those with severe mental health histories. While CTOs appear to benefit a sub section of CTO users, this is not a universal benefit (Riley, et al, 2016) and legal controls create resistance, ambivalence, and shame for users.

CTO journeys are complex, but they share intersectoral histories of social disadvantage and a need for social support and relationships. Practitioners know the limitations of a CTO, but share a homogenous perspective that it can represent a reduction of risk in a harsh social environment, which requires risk minimisation. Service users see a consistent relationship with a practitioner as important, given an ambivalence about legal coercion and medication. This therapeutic relationship is contrary to the legal process, but develops and exists because of the CTO.

\section{Acknowledgements}

This article presents independent research funded by the NIHR School for Social Care Research. (Ref) C088/T15-011/UBJS-P84. The views expressed in this article are those of the authors and not necessarily those of the NIHR School for Social Care Research or the Department of Health and Social Care, NIHR or NHS. Our thanks to the anonymous reviewers for their helpful comments and suggestions. 


\section{References}

Awara, M., Jaffar, K., and Roberts, P., 2013. Effectiveness of the Community Treatment Order in streamlining psychiatric services. Journal of Mental Health, 22, 191-197.

Banks, L., Stroud, J., and Doughty, K., 2016. Community treatment orders: exploring the paradox of personalisation under compulsion. Health and Social Care in the Community, 24, 181-190.

Boulton, J., Allen, P., and Bowman, C., 2015. Embracing Complexity: Strategy Perspectives for an Age of Turbulence. Oxford: Oxford University Press.

Braun, V., and Clarke, V., 2006. Using thematic analysis in psychology. Qualitative research in psychology, 3, 77-101.

Breit, E., Andreassen, T., and Salomon, R., 2016. Modification of Public Policies by StreetLevel Organisations: An Institutional Work Perspective. Journal of Social Policy, 45, 709-728.

Burns, T., 2009., Community supervision orders for the mentally ill: Mental health professionals' attitudes. Journal of Mental Health, 4, 301-308.

Burns, T., et al., 2013. Community treatment orders for patients with psychosis (OCTET): a randomised controlled trial. The Lancet, 381,(9878), 162.

Byrne, D., and Callaghan, G., 2013. Complexity Theory and the Social Sciences: The state of the art. Abingdon: Oxon: Routledge.

Castellani, B., and Hafferty, F., 2009. Sociology and Complexity Science: A New Area of Inquiry. New York: Springer.

Cilliers, P. 1998., Complexity and Postmodernism. London: Sage.

Care Quality Commission. 2016., Monitoring the Mental Health Act 2014-15. Newcastle: Stationery Office.

Darking, M., Haynes, P., and Stroud, J., 2018. Developing public service knowledge and learning about complex systems: using a community of practice to integrate theory and practice. Governance and Complexity, 4,1 [online] Available from: https://ubp.unibamberg.de/ojs/index.php/cgn/article/view/45 [Accessed $1^{\text {st }}$ October 2018].

Dawson, J., and Mullen, R., 2008. Insight and use of community treatment orders. Journal of Mental Health, 17, 269-280.

De Riddler, R., et al., 2016., Community treatment orders in the UK 5 years on: a repeat national survey of psychiatrists. BJPsyc Bulletin, 40, 119-123.

Disability Rights UK., 2017. Implementation of the United Nations Convention on the Rights of Persons with Disabilities in England and Wales. London: Disability Rights UK and Disability Wales [online] Available from: https://www.disabilityrightsuk.org/news/2017/january/disabled-people-tell-uncommittee-uk-failing-international-rights-convention [Accessed $23^{\text {rd }}$ September, 2018]. 
Dixon, J. 2015., Balancing risk and recovery in mental health: an analysis of the way in which policy objectives around risk and recovery affect professional practice in England. In J. M. Chamberlain, Medicine, risk, discourse and power. London: Routledge (120-140).

Edgren, L., and Barnard, K., 2012. Complex adaptive systems for management of integrated care. Leadership in Health Services, 25, 39-51.

Ellis, L., Churruca, K., and Braithwaite, J., 2017. Mental health services conceptualised as complex adaptive systems: what can be learned? International Journal of Mental Health Systems, 11, 1-5.

Gibbs, A., Dawson, J., Ansley, C., and Mullen, R., 2005. How patients in New Zealand view community treatment orders. Journal of Mental Health, 14, 357-368.

Hatfield, B., and Antcliff, V., 2001. Detention under the Mental Health Act: balancing rights, risks and needs for services. Journal of Social Welfare and Family Law 23, 135-153

Hawe, P., Shiell, A., and Riley, T., 2009. Theorising Interventions as System Events. American Journal of Community Psychology, 43, 267-276.

Haynes, P., 2008. Complexity Theory and Evaluation in Public Management: A qualitative systems approach. Public Management Review, 10, 401-420.

Haynes, P., 2012. Public Policy Beyond the Financial Crisis; an international comparative study. Abingdon, Oxon: Routledge.

Haynes, P., 2015. Managing Complexity in the Public Services (2nd ed.). Abingdon, Oxon: Routledge.

Haynes, P., 2017. Social Synthesis: understanding patterns in complex social systems. Oxon: Routledge.

Hyojung, K., et al., 2017. A systems thinking approach to prospective planning of interventions for chronic kidney disease care. Health Systems, 6, 130-147.

Janson, S., and Fridlund, B., 2016. Perceptions Among Psychiatric Staff of Creating a Therapeutic Alliance with Patients on Community Treatment Orders. Issues in Mental Health, 37, 701-707.

Kontopoulos, K. 1998., The Logics of Social Structure. Cambridge: Cambridge University Press.

Lipsky, S., 1980. Street-level Bureaucracy: Dilemmas of the Individual in Public Services. New York: Russell Sage Foundation.

Lorenz, E. N., 1963. Deterministic nonperiodic flow. Journal of the atmospheric sciences, 20, 130-141.

Luhmann, N., 1995. Social Systems. Stanford, CA: Stanford University Press.

Mahoney, J., 2000. Path dependence in historical sociology. Theory and society, 29, 507-548.

Meadows, D., 2009. Thinking in Systems: A Primer. London: Earthscan.

Moeller, H.G., 2006. Luhmann Explained: From Souls to Systems. Chicago: Open Court. 
National Confidential Inquiry into Suicide and Homicide by People with Mental Illness., 2017. Annual Report: England, Northern Ireland, Scotland and Wales. Manchester: University of Manchester.

NHS Digital., 2017. Mental Health Act Statistics, Annual Figures. NHS, England. Leeds: NHS, England [online]. Available from: https://digital.nhs.uk/data-andinformation/publications/statistical/mental-health-act-statistics-annual-figures/mentalhealth-act-statistics-annual-figures-2016-17-experimental-statistics [Accessed 31 ${ }^{\text {st }}$ August 2018].

Nohrstedt, D., and Weible, C., 2010. The Logic of Policy Change after Crisis: Proximity and Subsystem Interaction. Risk, Hazard and Crisis in Public Policy, 1, 1-32.

Pawson, R., and Tilley, N., 1997. Realistic Evaluation. London: Sage.

Plsek, P., and Greenhalgh, T., 2001. The challenge of complexity in health care. BMJ, 323, 625628.

Ragin, C., 1987. The Comparative Method: Moving beyound Qualitative and Quantitative Strategies. Berkeley, CA: University of California Press.

Rihoux, B., and Ragin, C., 2009. Configurational Comparative Methods: Qualitative Comparative Methods (QCA) and Related Techniques. London: Sage.

Riley, H., Fagerjord Lorem, G., and Hoyer, G., 2016. Community treatment orders - what are the views of decision makers? Journal of Mental Health, 27, 97-102.

Rogers, A., and Pilgrim, D. 2001. Mental health policy in Britain. London: Palgrave:Macmillan.

Rugkasa, J., 2016. Effectiveness of Community Treatment Orders: The International Evidence. The Canadian Journal of Psychiatry, 61, 15-24.

Salehi, A., Ehrlich, C., Kendall, E., and Sav, A., 2018. Bonding and bridging social capital in the recovery of severe mental illness: a synthesis of qualitative research. Journal of Mental Health [online]. Available from: https://doi:10.1080/09638237.2018.1466033 [Accessed $4^{\text {th }}$ July 2018]

Sanderson, I. 2000., Evaluation in Complex Policy Systems. Evaluation, 6, 433-454.

Seddon, J., 2008. Systems Thinking in the Public Sector. Axminister: : Triarchy Press.

Simon, H., 1962. The Architecture of Complexity. Proceedings of the American Philosophical Society, 106, 467-482.

Squires, P., 1990. Anti Social Policy: Welfare, Ideology and the Discipline State. London: Prentice Hall.

Stroud, J., and Haynes, P., 2018. Social Factors, Care and Community Treatment Orders (CTOs). Service User and Practitioner Perspectives. London: NHIR School for Social Care Research.[online]. Available from: https://www.sscr.nihr.ac.uk/wpcontent/uploads/RF84.pdf [Accessed $12^{\text {th }}$ December 2018]

Stroud, J., Banks, L., and Doughty, K., 2015. Community treatment orders: learning from experiences of service users, practitioners and nearest relatives. Journal of Mental Health, 24, 88-92. 
Stull, L., McGrew, J., and Salyers, M., 2012. Processes underlying treatment success and faiure in assertive community treatment. Journal of Mental Health, 21, 49-56.

Sturmberg, J. P., O'Halloran, D. M., and Martin, C., 2012. Understanding health system reform - a complex adaptive sysems perspective. Journal of Evaluation in Clinical Practice, 18, 202-208.

Teisman, G., van Buuren, A., and Gerrits, L., 2009. Managing Complex Government Systems: Dynamics, Self Organisation and Coevolution in Public Investments. London: Routledge.

Tsasis, P., Evans, J., and Owen, S., 2012. Reframing the challenges to integrated care; a complex-adaptive systems perspective. International Journal of Integrated Care [online], 1-11. Available from http://www.ijic.org/ [Accessed $1^{\text {st }}$ December 2018]

Vergunst, F., et al., 2017. Community treatment orders and social outcomes for patients with psychosis: a 48 month follow-up study. Soc Psychiatry Psychatric Epidemiol 52, 13751384.

Walby, S., 2007. Complexity Theory, Systems Theory, and Multiple Intersecting Social Inequalities. Philosophy of Social Sciences, 37, 449-470.

Weller, P., 2011. The Convention on the Rights of Persons with Disabilities and the social model of health : new perspectives. Journal of Mental Health Law (Spring), 74-83.

Wessely, S., Gilbert, S., Hedley, M. and Neuberger, R., 2018. Independent Review of the Mental Health Act Interim Report. London: Department of Health and Social Care [online]. Available from: https://www.gov.uk/government/publications/independent-review-ofthe-mental-health-act-interim-report [Accessed $26^{\text {th }}$ September 2018]

Zafonte, M., and Sabatier, P., 1998. Shared Beliefs and Imposed Interdependencies as Determinants of Ally Networks in Overlapping Systems. Journal of Theoretical Politics, 10, 473-505. 
Figure 1. Trends in CTO decisions and activities

Source: derived from public information at the HSCIC, 2015, table 3, KP90 http://www.hscic.gov.uk

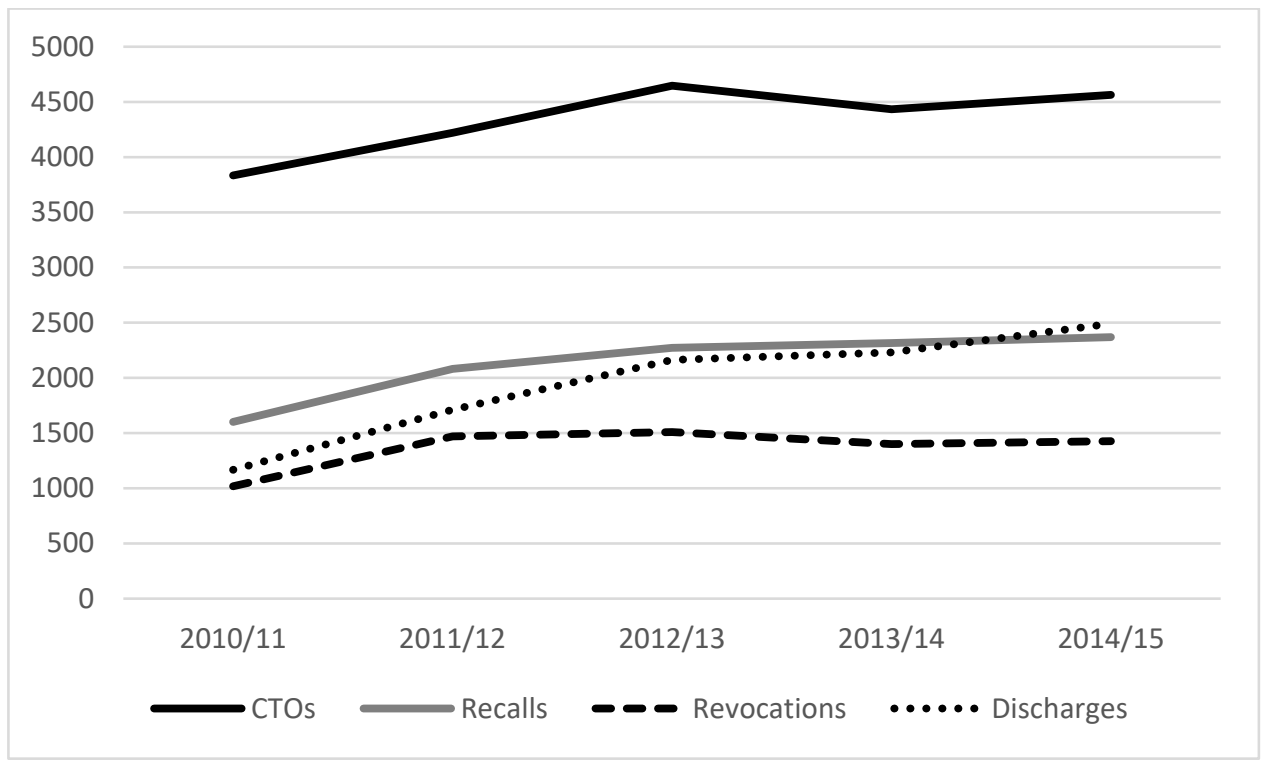


Figure 2 The ratio of CTOs made by registered mental health service providers, as compared with Mental Health Act detentions, 2015

Source: Derived from public information at the Health and Social Care Information Centre (HSCIC), 2015. http://www.hscic.gov.uk

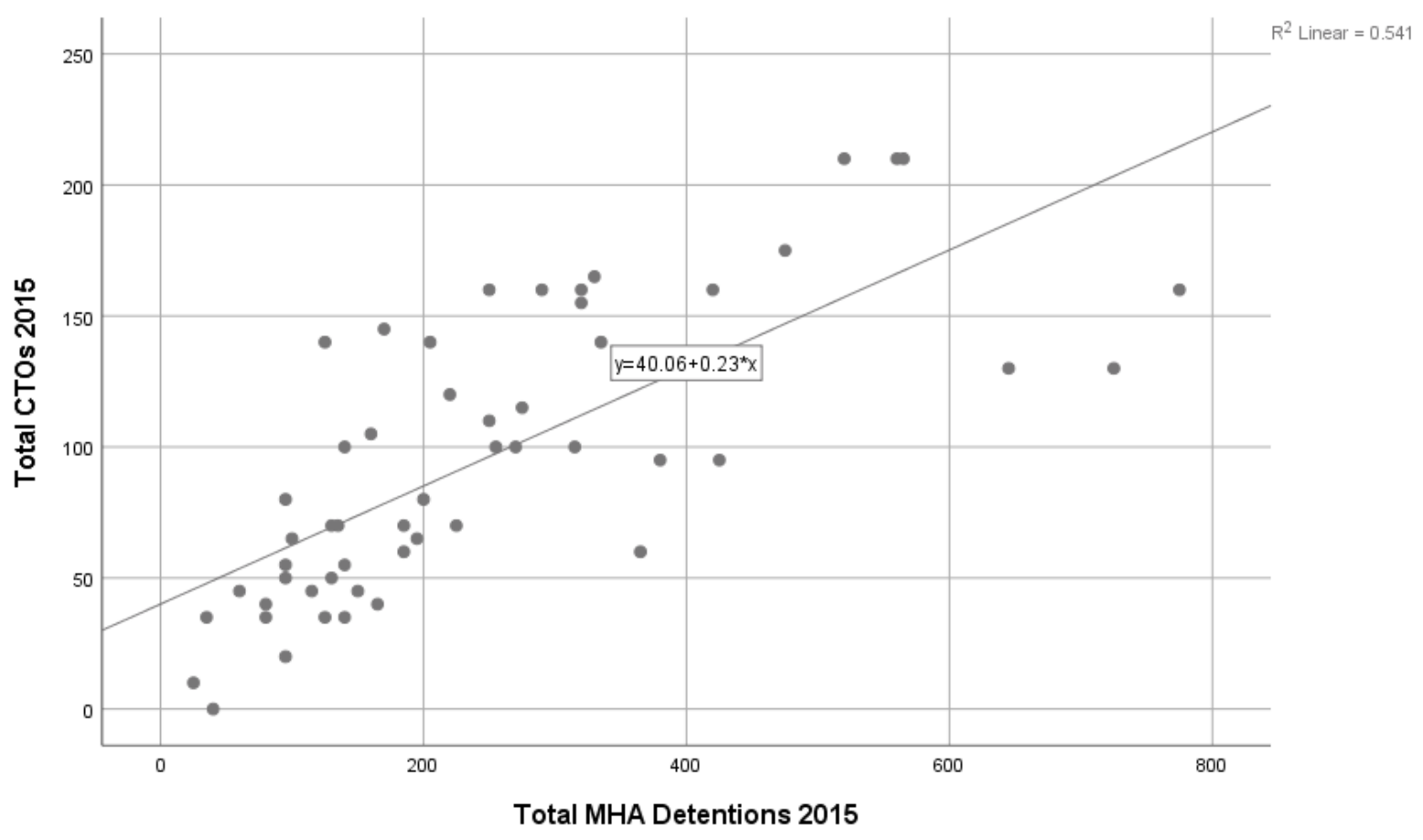

